\title{
Retraction Note to: Improved AODV Based on TOPSIS and Fuzzy Algorithms in Vehicular Ad-hoc Networks
}

\author{
Esmaeil Amiri ${ }^{1} \cdot$ Reza Hooshmand ${ }^{2}$ (i) \\ Published online: 22 December 2020 \\ (c) Springer Science+Business Media, LLC, part of Springer Nature 2020
}

\section{Retraction Note to: Wireless Personal Communications (2020) 111:947-961 https://doi.org/10.1007/s11277-019-06894-x}

The Editor-in-Chief has retracted this article [1] because it contains material that substantially overlaps with the following article [2]. All authors do not agree to this retraction.

\section{References}

1. Amiri, E., \& Hooshmand, R. (2020). Improved AODV based on TOPSIS and fuzzy algorithms in vehicular ad-hoc networks. Wireless Personal Communications, 111, 947-961. https://doi.org/10.1007/ s11277-019-06894-x.

2. Amiri, E., \& Hooshmand. R. (2019). Improving AODV with TOPSIS algorithm and fuzzy logic in VANETs. In 2019 27th Iranian Conference on Electrical Engineering (ICEE) 2019 April 30 (pp. 1367-1372). IEEE. https://doi.org/10.1109/IranianCEE.2019.8786427.

Publisher's Note Springer Nature remains neutral with regard to jurisdictional claims in published maps and institutional affiliations.

The original article can be found online at https://doi.org/10.1007/s11277-019-06894-X.

Reza Hooshmand

rhooshmand@ssau.ac.ir

Esmaeil Amiri

esmelmiri@gmail.com

1 Department of Electrical and Computer Engineering, Isfahan University of Technology, Isfahan, Iran

2 Department of Electrical Engineering, Shahid Sattari Aeronautical University of Science and Technology, Tehran, Iran 